Ege Tıp Dergisi / Ege Journal of Medicine 2019; 58 (4): 375-383

\title{
Bornova İlçesi'nde dört okulda ergenlerde internet bağımlılığı ve güvenli internet kullanımının değerlendirilmesi
}

\section{Evaluation of internet addiction and safe internet use in adolescents of four schools located in Bornova district}

\author{
Hilal Sipahi ${ }^{1} \quad$ Ekin Kartal ${ }^{2}$ \\ Süheyla Yoldaş ${ }^{1}$ Suna Yabar $^{1}$ (D) \\ Berke Gökkılıç ${ }^{2}$ Hatice Demir ${ }^{1}$ (D) \\ Melek Sarıül $1^{1}$ Vahap Tevfik Oğuz ${ }^{1}$ (iD \\ Özge May ${ }^{1}$ (D) \\ Ahmet Enis Özdemir ${ }^{1}$ \\ ${ }^{1}$ Bornova İlçe Sağlık Müdürlüğü, İzmir, Türkiye \\ ${ }^{2}$ Ege Üniversitesi, Tıp Fakültesi, İzmir, Türkiye
}

\section{Öz}

Amaç: Bu çalışmada İzmir'in nüfusu en büyük ilçelerinden Bornova İlçesi'nde belirlenen dört pilot okulda internet bağımlılığı prevalansının değerlendirilmesi amaçlanmıştır.

Gereç ve Yöntem: Bu kesitsel çalışmada araştırma grubunu Bornova ilçesindeki iki devlet ve iki özel okulun 6., 7., 9. ve 10. sınıflarındaki 1035 öğrenci oluşturdu. Veri toplama aracı olarak, Günüç ve Kayri'nin 2009 yılında geliştirdiği “internet bağımlılık ölçeği” ve kişisel anket formu kullanıldı.

Bulgular: Çalışma grubundaki 1035 öğrencinin 685'ine ulaşıldı. Formları uygun şekilde doldurmayan 24 öğrenci çalışma dışında bırakıldı; \%63,9'u $(n=661)$ analize alındı. İnternet bağımlılık ölçeğine göre öğrencilerin \%37,4'ü ( $n=247)$ internet bağımlısı değilken, \%36,9'u $(n=244)$ risk grubundaydı ve \%25,7'si $(n=170)$ ise internet bağımlısıydı. İnternet bağımlılık durumları ile güvenli internet kullanma $(x 2=9,013$; $p=0,011)$, günlük bilgisayar oyunu oynama $(x 2=76,556 ; p=0,000)$, televizyon izleme $(x 2=11,859$; $p=0,003)$, öğrencinin internet hakkında evde bilgilendirilmesi $\left(x^{2}=19.386 ; p<0,001\right)$ ve internete bağlanma süresi (x2=61,787; $p<0,000)$, internet kullanmaya başlama yaşı $(x 2=23,360 ; p<0,000)$ arasında istatistiksel olarak anlamlı ilişki saptandı.

Sonuç: Verilerimiz öğrencilerin azımsanmayacak kısmının "internet bağımlıı” olduğunu göstermektedir. Bu konuda daha ileri araştırmalar ve koruyucu çalışmalar yapılmasında fayda vardır.

Anahtar Sözcükler: Okul, ergen, internet bağımlılığı, internet bağımlılık ölçeği.

\section{Abstract}

Aim: In this study it was aimed to evaluate the prevalence of Internet addiction in four pilot schools located in Bornova, one of Izmir's most populated districts.

Material and Methods: In this cross-sectional study the study sample comprised 1035 students in grade 6, 7, 9 and 10 of two state and two private schools located in Bornova district. The tools were "Internet addiction scale" developed by Günüç and Kayri in 2009 and a personal questionnaire form.

Results: We reached 685 of 1035 students in the study sample. Twenty-four students who did not fill the questionnaire properly were excluded and a total of 661 students (63.9\%) were included in the analysis. According to Internet addiction scale, 37.4\% (n=247) were not Internet addict while $36.9 \%(n=244)$ were in the risk group and $25.7 \%(n=170)$ were Internet addict. Internet addiction was significantly associated with safe Internet use $(x 2=9,013 ; p=0,011)$, daily personnel computer game playing $(x 2=76,556$; $p=0,000)$, watching television $(x 2=11,859 ; p=0,003)$, Internet connection time $(x 2=61,787 ; p=0,000))$, informing the student at home about internet $\left(x^{2}=19.386 ; p<0,001\right)$ and age for starting Internet use $(x 2=23,360 ; p=0,000)$.

\footnotetext{
Yazışma Adresi: Hilal Sipahi

Bornova İlçe Sağlık Müdürlüğü, İzmir, Türkiye

E-mail: hilalsipahi@gmail.com

Makalenin Geliş Tarihi: 09.09.2018 Kabul Tarihi: 31.10.2018
} 
Conclusion: These data suggest that a substantial part of the students is Internet addict. Hence, further interventional studies are needed for prevention.

Keywords: School, adolescents, internet addiction, internet addiction scale.

\section{Giriş}

İnternet, insanların her türlü bilgiye çok kısa bir zamanda ulaşmasını ve diğer insanlarla çok hızlı bir şekilde iletişim kurabilmesini sağlayarak insan yaşamına önemli katkılar getiren bir iletişim aracıdır.

Günümüzde bu iletişim aracının kullanımı inanılmaz bir hızla artmıştır (1). TÜík'in 2013 2017 yıllarında 'Hanelerde Bilişim Teknolojileri Kullanımı' 16-74 yaş grubu bireylerde internet kullanımı çalışmalarına göre ise internet kullanıcısı oranı \%48,9'dan \%66,8'a çıkmıştır $(2,3)$.

İnternet, bilgi ve iletişim kaynağı olarak birçok potansiyeli yanında önemli sorunları da beraberinde getirmekte ve birçok tehlikeyi içerebilmektedir. İnternet bağımlıı̆̆ (IB), internet ve bilgisayarın aşırı kullanımına bağı fiziksel, ruhsal ve sosyal problemlerin ortaya çıkması şeklinde tanımlanmaktadır (1). Bu bağlamda internetin öneminin ve çevrimiçi kullanım süresinin dikkate değer şekilde artmasıyla internet bağımlıı̆ı̆ı toplumda azımsanmayacak sıklıkta görülür hale gelmiştir (4). Cheng ve arkadaşlarının 31 ülkeyi kapsayan 2014 tarihli 12-41 yaş aralığındaki raporlar üzerine yaptıkları metaanalizde (ortalama yaş 18, 42), İB prevalansı orta doğuda $\% 10,9,31$ ülkenin tamamında ise \%6 bulunmuştur (5). İB'nin iş ve arkadaş ilişkilerine, akademik kariyere aile yaşamına olumsuz etkileri olabilmektedir (6), ayrıca nöronal anormalliklerle ve kognitif disfonksiyonla olan ilişkisi gösterilmiştir $(7,8)$. Üstelik internet bağımlılığı dikkat eksikliği hiperaktivite bozukluğu ve depresyon gibi psikiyatrik bozukluklarla komorbidite göstermektedir $(9,10,11)$.

IB her yaşta görülebilmesine karşın en büyük risk grubu 12-18 yaş arası gençlerdir (12). Çocuklar üzerinde yapılan çalışmalar incelendiğinde, uzun süre internet kullanan ve zamanını bilgisayar oyunlarıyla geçiren çocukların sosyal gelişimlerinin önemli ölçüde gerilediği; özgüvenlerinin düşük, sosyal anksiyete düzeylerinin yüksek olduğu ve agresif davranışlarda artışın gözlendiği söylenebilir (13).
Çocuğun, ailenin ve eğitimcilerin İB hakkında farkındalığının ve durumu değerlendirme becerisinin olması müdahale şansını ve başarısını arttıracaktır. Konuyla ilgili dünyada hatırı sayılır miktarda çalışma olmasına rağmen İzmir ve Ege Bölgesi'ndeki veri sınırlıdır (14). Bu çalışmada İzmir'in en büyük ilçelerinden Bornova İlçesi'nde belirlenen dört pilot okulda internet bağımlılığı sıklığının değerlendirilmesi amaçlanmıştır.

\section{Gereç ve Yöntem}

Kesitsel tipte planlanan bu çalışmada araştırma grubunu Bornova ilçesindeki iki devlet ve iki özel okulun 6., 7., 9. ve 10. sınıflarındaki 1035 öğrenci oluşturmaktadır.

Veri toplama aracı olarak, Günüç ve Kayri'nin 2009 yılında geliştirdiği otuz beş maddeden oluşan “internet bağımlılık ölçeği” kullanıldı (15). Ölçeğin yanında, sosyodemografik özellikler ve güvenli internet kullanımını saptamaya yönelik, ergenin internet kullanım bilgi ve davranışını da sorgulayan toplam 48 sorudan oluşan anket uygulandı.

Güvenli internet kullanımı ile ilgili değerlendirme için bilgi ve davranışları içeren 18 sorudan elde edilen güvenli internet kullanımı puanlarının ortalaması alınarak kestirim noktası belirlendi ve elde edilen skorlara göre öğrencilerin güvenli internet kullanımı durumu belirlendi.

Veriler 2013-2014 öğrenim yılının ikinci döneminde, çalışma günü okulda mevcut olan tüm öğrencilere sınıflarında ders saati içerisinde gözlem altında veri toplama formu aracılığı ile toplandı. Öğretmenlere ve velilere formlar gönderilerek doldurmaları istendi.

Çalışma izinleri İzmir İ Sağlık Müdürlüğü, Bornova Kaymakamlığı İlçe Milli Eğitim Müdürlüğü'nden alındı.

Veriler SPSS 21.0 istatistik paket programı ile analiz edildi, analizde demografik veriler için tanımlayıcı istatistiklerden yararlanıldı. Öğrencilerin internet bağımlıı̆̆ durumunu belirlemek için internet bağımlılık ölçeğinden elde edilen veriler "iki aşamalı kümeleme analizi” ile değerlendirildi. 
Bulgular

Çalışma grubundaki 1035 öğrencinin 685'ine ulaşıldı. Formları uygun şekilde doldurmayan 24 öğrenci çalışma dışında bırakıldı; \%63,9'u ( $n=661)$ analize alındı.
Öğrencilerin 181’i $(\% 27,4) 6$. sınıf, 183'ü $(\% 27,6)$ 7. sınıf, 161'i (\%24,4) 9. sınıf ve 136'sı (\%20,6) 10. sınıfa devam etmekte iken 342'si $(\% 51,7)$ kız ve 319 'u $(\% 48,3)$ erkekti. Öğrencilerin annelerinin \%43,7'si (n=283), babalarının \%54,5'i $(n=348)$ üniversite mezunuydu (Tablo-1).

Tablo-1. Çalışma grubunun sınıf-cinsiyet ve anne/baba eğitim durumu.

\begin{tabular}{|c|c|c|c|}
\hline Değişkenler & & $\mathbf{n}$ & $\%$ \\
\hline \multirow[t]{5}{*}{ Sınıf Düzeyi } & 6. Sinıf & 181 & 27,4 \\
\hline & 7. Sınıf & 183 & 27,6 \\
\hline & 9. Sinıf & 161 & 24,4 \\
\hline & 10. Sınıf & 136 & 20,6 \\
\hline & Toplam & 661 & 100,0 \\
\hline \multirow[t]{3}{*}{ Cinsiyet } & Erkek & 319 & 48,3 \\
\hline & $\mathrm{K} \mathrm{IZ}$ & 342 & 51,7 \\
\hline & Toplam & 661 & 100,0 \\
\hline \multirow[t]{4}{*}{ Anne Eğitim Durumu } & Orta okul ve altı & 143 & 22,1 \\
\hline & Lise & 221 & 34,2 \\
\hline & Üniversite ve üstü & 283 & 43,7 \\
\hline & Toplam & 647 & 100,0 \\
\hline \multirow[t]{4}{*}{ Baba Eğitim Durumu } & Orta okul ve altı & 107 & 16,7 \\
\hline & Lise & 184 & 28,8 \\
\hline & Üniversite ve üstü & 348 & 54,5 \\
\hline & Toplam & 639 & 100,0 \\
\hline
\end{tabular}

Tablo-2. Çalışma grubunun internet kullanmaya başlama yaşı, internete bağlanma, televizyon izleme ve bilgisayar oyunu oynama süresi.

\begin{tabular}{llcc}
\hline Değişkenler & & $\mathbf{n}$ & $\%$ \\
\hline $\begin{array}{l}\text { Interneti kullanmaya } \\
\text { başlama yaşı }\end{array}$ & $0-5$ yaş & 100 & 16,4 \\
& $6-10$ yaş & 443 & 72,5 \\
& 11 yaş ve üstü & 68 & 11,1 \\
Günlük internete bağlanma saati & Toplam & 611 & 100 \\
& 2 saatten az & 431 & 65,7 \\
& 2 saat ve üstü & 225 & 34,3 \\
Günlük televizyon izleme saati & Toplam & $\mathbf{6 5 6}$ & $\mathbf{1 0 0}$ \\
& 2 saatten az & 546 & 82,76 \\
& 2 saat ve üstü & 115 & 17,4 \\
Günlük bilgisayar oyunu & Toplam & $\mathbf{6 6 1}$ & $\mathbf{1 0 0}$ \\
oynama saati & 2 saatten az & 546 & 83,5 \\
& 2 saat ve üstü & 108 & 16,5 \\
& Toplam & $\mathbf{6 5 4}$ & $\mathbf{1 0 0}$ \\
\hline
\end{tabular}


Tablo-3. Çalışma grubunun bilgisayara, cep telefonuna sahip olma ve internete erişim durumu.

\begin{tabular}{|c|c|c|c|}
\hline Değişkenler & & $\mathbf{n}$ & $\%$ \\
\hline \multirow[t]{3}{*}{ Bilgisayara Sahip Olma Durumu } & Evet & 638 & 96,5 \\
\hline & Hayır & 23 & 3,5 \\
\hline & Toplam & 661 & 100,0 \\
\hline \multirow[t]{3}{*}{ Evde İnternete Erişim Durumu } & Var & 627 & 95,1 \\
\hline & Yok & 32 & 4,9 \\
\hline & Toplam & 659 & 100,0 \\
\hline \multirow[t]{3}{*}{ Cep telefonu sahipliği } & Var & 605 & 91,7 \\
\hline & Yok & 55 & 8,3 \\
\hline & Toplam & 660 & 100,0 \\
\hline Cep telefonundan internete & Var & 532 & 81,6 \\
\hline \multirow[t]{2}{*}{ erişim } & Yok & 120 & 18,4 \\
\hline & Toplam & 652 & 100,0 \\
\hline \multirow[t]{4}{*}{ İnternete Erişim Ortamı } & Ev & 605 & 92,1 \\
\hline & İnternet Kafe & 113 & 17,2 \\
\hline & Okul & 162 & 24,7 \\
\hline & Diğer & 159 & 24,2 \\
\hline
\end{tabular}

Tablo-4. İnternet bağımlılık durumuna göre güvenli internet kullanımı durumu.

\begin{tabular}{|c|c|c|c|c|c|}
\hline & & \multicolumn{3}{|c|}{ İnternet Bağımlılığı } & \multirow[b]{2}{*}{$\mathbf{p}$} \\
\hline & & $\begin{array}{c}\text { Internet } \\
\text { bağımlısı } \\
\text { olmayanlar }\end{array}$ & Risk grubu & $\begin{array}{l}\text { Internet } \\
\text { bağımlısı }\end{array}$ & \\
\hline \multirow{2}{*}{$\begin{array}{l}\text { Güvenli internet } \\
\text { kullanımı }\end{array}$} & Yok & $128(\% 32,9)$ & $149(\% 38,3)$ & $112(\% 28,8)$ & \multirow{2}{*}{0,011} \\
\hline & Var & $119(\% 43,8)$ & $95(\% 34,9)$ & $58(\% 21,3)$ & \\
\hline \multirow{2}{*}{$\begin{array}{c}\text { Günlük bilgisayar } \\
\text { kullanımı }\end{array}$} & 2 saat altı & $231(\% 42,3)$ & $209(\% 38,3)$ & $106(\% 19,4)$ & \multirow{2}{*}{0,000} \\
\hline & 2 saat ve daha fazla & $12(\% 11,1)$ & $32(\% 29,6)$ & $64(\% 59,3)$ & \\
\hline \multirow{2}{*}{$\begin{array}{c}\text { Günlük televizyon } \\
\text { izleme }\end{array}$} & 2 saat altı & $217(\% 39,7)$ & $202(\% 37,0)$ & $127(\% 23,3)$ & \multirow{2}{*}{0,002} \\
\hline & 2 saat ve daha fazla & $30(\% 26,1)$ & $42(\% 36,5)$ & $43(\% 37,4)$ & \\
\hline \multirow{2}{*}{$\begin{array}{l}\text { Günlük internete } \\
\text { bağlanma süresi }\end{array}$} & 2 saat altı & $197(\% 45,7)$ & $160(\% 37,1)$ & $74(\% 17,2)$ & \multirow{2}{*}{0,000} \\
\hline & 2 saat ve daha fazla & $47(\% 20,9)$ & $82(\% 36,4)$ & $96(\% 42,7)$ & \\
\hline \multirow{3}{*}{$\begin{array}{l}\text { Internet kullanmaya } \\
\text { başlama yaşı }\end{array}$} & $0-5$ yaş & $24(\% 24)$ & $32(\% 32,0)$ & $44(\% 44,0)$ & \multirow{3}{*}{0,000} \\
\hline & 6-10 yaş & $166(\% 37,5)$ & $168(\% 37,9)$ & $109(\% 24,6)$ & \\
\hline & 11 yaş ve üstü & $34(\% 50,0)$ & $24(\% 35,3)$ & $10(\% 14,7)$ & \\
\hline
\end{tabular}


Grubun \%88,9'unun internet kullanmaya başlama yaşı 10 yaş ve altındaydı $(n=543)$. Araştırma grubunun \%82,8'inin (n:546) günlük televizyon izleme suresi, \%65,7'sinin ( $n=431)$ günlük internete bağlanma süresi, \%83,5'nin $(n=546)$ günlük bilgisayar oyunu oynama süresi iki saat ve altındaydı (Tablo-2).

Öğrencilerin evlerinde \%96,5'inin ( $n=638)$ bilgisayarı, \%95,1'inin internet bağlantısı bulunmakta iken \%91,7'sinin $(n=605)$ cep telefonu ve $\% 81,6$ 'sının $(n=532)$ cep telefonundan internet erişimi vardı ve \%92,1'i $(n=605)$ internete evinden bağlanmaktaydı (Tablo-3).

Internet bağımlılık ölçeğine göre öğrencilerin \%37,4'ü (n=247) internet bağımlısı değilken, $\% 36,9$ 'u ( $n=244)$ risk grubundaydı ve \%25,7'si $(n=170)$ ise internet bağımlısıydı.

Güvenli internet kullanımı ile ilgili bilgi ve davranışları içeren sorulardan elde edilen güvenli internet kullanımı puanlarının ortalaması alınarak kestirim noktası belirlendi ve elde edilen skorlara göre öğrencilerin $\% 41,1^{\prime} i(n=389)$ interneti güvenli bir biçimde kullanabilmeydi ve internet bağımlıları, risk grubundakiler ve internet bağımlısı olmayanlar arasındaki fark anlamlıydı (Tablo-4). Internet bağımlılık durumlarına göre incelendiğinde anne eğitimi, baba eğitimi, annenin, babanın hayatta olması, annenin, babanın işi, öğrencinin okul başarısı algısı, internet hakkında öğrencinin okulunda bilgilendirilmesi, sosyal paylaşım hesabının bulunması, hesap açma yaşı, sosyoekonomik durum, annenin, babanın evde internet kullanması arasında çok gözlü ki-kare testlerinde istatistiksel olarak anlamlı bir fark saptanmadı. Ancak internet bağımlılık durumları ile güvenli internet kullanma $\left(x^{2}=9,013 ; p=0,011\right)$, günlük bilgisayar oyunu oynama $\left(x^{2}=76,556\right.$; $p<0,001)$, televizyon izleme $\left(x^{2}=11,859 ; p=0,003\right)$, öğrencinin internet hakkında evde bilgilendirilmesi $\left(x^{2}=19.386 ; p<0,001\right)$ ve internete bağlanma süresi $\left(x^{2}=61,787 ; p<0,001\right)$, internet kullanmaya başlama yaşı $\left(x^{2}=23,360 ; \quad p<0,001\right)$ arasında istatistiksel olarak anlamlı ilişki saptandı (Tablo-4).

\section{Tartışma}

Çalışmamızda, İzmir ili Bornova ilçesinde dört pilot okulda internet bağımlılığı prevalansı ve çeşitli değişkenlerin İB üzerindeki etkisi irdelenmiş, çalışmaya katılanların \%25,7'si internet bağımlısı, $\% 36,9$ 'u ise risk gurubunda bulunmuştur.
TÜİK tarafından 2013 yılında, 6-15 yaş grubunu içeren Hane halkı Bilişim Teknolojileri Kullanımı Araştırması'na göre bilgisayar kullanmaya ortalama 8 yaşında başlandığı görülmektedir. İnternet kullanımına başlama yaşının ise 9 olduğu saptanmıştır, 6-15 yaş grubundaki çocukların $\% 24,4$ 'ü kendi kullanımına ait bilgisayara, \%13,1'i cep telefonuna ve $\% 2,9$ 'u oyun konsoluna sahiptir $(16,17)$. Literatürde de teknolojiyle ve internetle erken yaşlarda tanışıldığı görülmektedir. Avrupa Çevrimiçi Çocuklar Araştırma Projesi (18) kapsamındaki araştırmaya katılan 9-16 yaş arasındaki çocukların internet kullanımının 10 yaş civarında başladığı belirtilmektedir. Çalışmamızda da internet kullanmaya başlama yaşı 6 yaş ve altında olanlar $\% 88,9$ ile çoğunluğu oluşturmaktayken, katılımcıların \%72,5'inin internet kullanımına başlama yaşı 6-10 yaş arasındadır.

Dünya genelinde internet bağımlısı, problemli ya da patolojik internet kullanıcısı olarak tanımlanan gençlerin yaygınlığı \%1,6 ile \%26,3 arasında değişmektedir $(19,29)$. Cheng ve arkadaşlarının 2014 tarihli meta-analizine göre dünyanın çeşitli yerlerinde İ prevalansı yaştan bağımsız olarak $\% 2,6$ ile \%10,9 arasında değişmektedir (5). Ayrıca farklı literatürler incelendiğinde ỉ prevalansı ABD'de \%0-26,3 arasında (28) değişmekle birlikte $A B$ ülkelerinde ise \%18,3'e kadar çıkabilmektedir (23). Durkee ve ark. Avrupa genelinde yaptıkları çalışmada İB prevalansının \%3,1 ile 18,3 arasında değiştiğini, İB prevalansı ile ilgili epidemiyolojik çalışmaların ülkeye ve cinsiyete göre ciddi varyasyonlar gösterdiğini belirtmiştir (30). Türkiye'nin çeşitli illerinde ise ilkokul, ortaokul ve üniversite öğrencilerinde yapılan çalışmalarda IB prevalansı \%1,1 ile \%23,2 arasında değişmektedir $(4,6,14,31-38)$. Fakat bu çalışmalarda kullanılan İB ölçekleri kendi aralarında farklılık göstermektedir. Dolayısıyla bu durum sonuçları etkileyebilir. Çalışmamızla aynı ölçeği kullanan Yılmaz ve arkadaşlarının sonuçlarına göre öğrencilerin \%16,3'ünün (34), başka bir çalışmaya (14) göre de \%12,6'sının internet bağımlısı olduğu görülmektedir. Bizim çalışmamızda ise İ prevalansı \%25,7 bulunmuştur. Türkiye genelinde yapılan çalışmalarda bulunan farklı değerlerin sebepleri arasında da aynı şekilde ülkedeki bölgesel-kültürel farklılıkların varlığı ve homojen bir yapının olmaması, çalışmalarının tarihleri (verilerin toplanma zamanları arasında geçen yıllara bağlı 
olarak internete erişiminin daha kolaylaşması ve yaygınlaşması) arasındaki farklııılar ve çalışmanın sadece Bornova ilçesi ile sınırlandırılması gösterilebilir. Ayrıca ilerleyen çalışmalarda öğrencilerin okuldaki başarılarının, okuma alışkanlıklarının, hobilerinin, spora ve kültürelsanatsal aktivitelere ayırdıkları zamanın da incelenmesi gözlenen bu farkın daha sağlıklı değerlendirilmesinde yararlı olacaktır (6).

Çalışmamızda ebeveynlerin eğitimi, sosyoekonomik durumu ve evde internet kullanımı ile IB arasında istatistiksel anlamlı bir ilişki saptanmamıştır. Literatürde de bu parametreler ile IB arasında anlamlı bir ilişki saptanmayan çeşitli çalışmalar vardır $(4,12,39,40)$. Ekonomik düzeyin artmasıyla internete girme sıklığı artmakla birlikte bu durum internet bağımlılığı ile ilişkilendirilmemiştir (4). Anne eğitimi ile ilgili olarak ise Batıgün ve arkadaşları üniversite öğrencilerinde yaptıkları bir çalışmada, bu ölçütü sosyoekonomik düzey değişkeni olarak ele almış, yüksek eğitimli annelerin çocukları orta ve alt düzeyde bulunan bireylere göre anlamlı düzeyde daha yüksek bağımlılık puanları almıştır (36). Şaşmaz ve arkadaşları ise anne eğitiminin internet bağımlıı̆ı̆ını azalttığı sonucuna ulaşmıştır, fakat onlar da ekonomik durumla ilgili bir ilişki saptayamamışlardır (6). Ayrıca çalışmamızda ebeveynlerde üniversite ve üstü eğitimin toplumun geneline göre, annede $(\% 43,7)$ ve babada $(\% 54,5)$ ile yüksek oranlarda olması değerlendirmede sınırılık yaratmıştır.

Ebeveyn eğitim düzeyi ve sosyoekonomik durumu ile IB arasındaki ilişki çalışmamızda istatistiksel olarak anlamlı bulunmamış olmakla birlikte kişinin internet bağımlısı olmasında ailenin önemli bir etkisi olduğu unutulmamalıdır. Yetersiz aile desteği, aile içi zayıf ilişkiler, çatışma ortamı ve yetersiz psikososyal desteğin varlığında İB'nin orantısız bir biçimde sık görüldüğü gözlenmiş, ailenin zayıf mental durumunun ise daha ciddi bir bağımlıık ile ilişkili olduğu gösterilmiştir (11). Aileden gelen artan sosyal destek ise aksine IB ile ters orantılı olarak anlamlı bulunmuştur (11). Bu bakımdan çalışmamızda bulunan internet hakkında evinde yeterince ve çok bilgilendirildiğini düşünen öğrencilerde İB'nin anlamlı olarak düşük olması literatürle örtüşmektedir ve ailenin konuya yaklaşımının önemini ortaya koymaktadır. Eğitim seviyesinden bağımsız olarak ebeveynler çocukların internet kullanımını sınırlandırmakta zorluk çekiyor olabilir ve/veya sosyoekonomik seviye arttıkça çocukların internete ulaşımının kolaylaşması ile eğitim seviyesinin etkisi bir miktar azalıyor olabilir. Gelecek çalışmalarla IB ve ailesel değişkenler arasındaki ilişki daha ayrıntılı bir şekilde incelenmelidir.

Günlük internete bağlanma süresinin internet bağımlıı̆̆ı ile ilişkisi değerlendirildiğinde, günde iki saatten fazla bilgisayarda zaman geçirenlerde internet bağımlıı̆ı sıklığının daha yüksek olduğu görülmüştür $(p=0,000)$. Benzer çalışmalarda da haftalık internette zaman geçirme süresi izlenmiş ve yakın sonuçlara ulaşılmıştır $(39,41)$. İzmir'de 2013 yılında 12-18 yaş grubundaki 546 öğrencide yapılan başka bir çalışmada araştırmaya katılan ergenlerden internet bağımlısı olanların ortalama haftalık internet kullanım süresi 23,7 saat, risk grubundakilerin 16,9 saat, bağımlı olmayanların ise 8,8 saat bulunmuştur. Örneklemin ortalama internet kullanım süresi ise 13,8 saat olarak hesaplanmıştır (14). Sonuç olarak, bu çalışmaya göre bağımlı olmayan ve risk grubunda olan ergenlerin haftalık internet kullanım süreleri günde iki saati geçmemekle birlikte bağımlı grubun ortalama internet kullanım süresi günde iki saati aşmaktadır. Çalışmamızda da bağımlı olmayanların \%80,7'si, risk grubundakilerin ise $\% 66,1^{\prime} i$ günde iki saatten az; bağımlıların ise $\% 56,4$ 'ü günde iki saatten fazla bilgisayar kullanmaktaydı.

Tahiroğlu ve arkadaşları çalışmaya katılanların $\% 44,6$ 'sının haftada 1-2 saat, \%7,6'sının ise haftada 12 saat üzerinde internet kullandığını belirtmiş (42); bizim çalışmamızda ise haftada 14 saat üzerinde internet kullanma oranı \%34,2 bulunmuştur. Durum incelendiğinde $\% 7,6$ ile $\% 34,2$ arasındaki bu dramatik farkın olası sebeplerinden biri, yapılan bu iki çalışmanın tarihleri arasındaki fark olabilir. Bu sayede ayrıca aradan geçen süre dahilinde ergenlerin günlük hayatlarında internet kullanım süresinin artış göstermekte olduğu yorumu yapılabilir. İleride farklı tarihlerde yapılan IB çalışmalarını karşılaştıran meta-analiz çalışmalarının yapılması ile internet kullanım sıklığının ve İB'nin ergenlerde artma eğiliminde olup olmadığının yorumu daha sağlıklı yapılabilir.

Çalışmamızda günlük internet kullanımı yanında bilgisayar kullanım süresi ve IB arasında anlamlı ilişki bulunmuştur $(p=0,000)$. Şaşmaz ve 
arkadaşlarının yaptığı çalışmada öğrencilerin \%79'unun evinde bilgisayarı, \%38,4'ünün kendine ait bilgisayarı ve $\% 64,0$ 'ünün evinde internet bağlantısı olup öğrencilerin \%15,1'i internet bağımlısı olarak tespit edilmiştir (6). Bizim çalışmamızda da öğrencilerin \%96,5'inin $(n=638)$ evinde bilgisayar olduğunu ve \%92,1'inin $(n=605)$ internete evde girdiğini varsayarsak ulaşılan sonucun çok da şaşırtıcı olmadığı düşünülmektedir. Fakat İzmir'de yapılan bir başka çalışmada evde bilgisayar veya evdeki bilgisayarda internet bağlantısı bulundurma ile İ arasında anlamlı farklılık olmadığı gözlemlenmiştir (14). Ayrıca bizim çalışmamızda da öğrencilerin \%83,5 gibi bir kısmının günde iki saatin altında bilgisayar kullandığı düşünüldüğünde, bizim sonuçlarımız da ulaşılan sonucu dolaylı olarak doğruluyor gibi görünmektedir. Fakat bizim verilerimiz, evinde bilgisayar bulundurmasına bakılmaksızın bütün katıımcı öğrencilerin bilgisayar kullanma süresi ile IB ilişkisini göstermektedir; evinde bilgisayar bulundurma ile bilgisayar kullanım süresinin arasında nasıl bir ilişki olduğunu ortaya koymamaktadır. Evinde bilgisayar bulunduran öğrencilerin günlük bilgisayar kullanma süreleri ile ilgili yapılacak bir çalışma konu hakkında daha kesin bilgiler verebilir.

Çalışmamıza katılanların \%83,5'inin bilgisayar kullanım süresinin günde iki saatin altında olması, sonuçlarımızın halihazırda var olan literatür ile uyumlu olduğunu göstermektedir. Yang da günlük internet kullanıcılarının \%87,7 oranında günde 1,52 saat bilgisayar kullanımı olduğu sonucuna ulaşmıştır. Ayrıca Yang çalışmasında bilgisayarın $\% 63,4$ oranında minimal, $\% 30,5$ oranında ılımlı ve $\% 6,1$ oranında ise aşırı kullanımının söz konusu olduğunu belirtmiştir (43).

Çalışmamızda günlük televizyon izleme süresi ile IB arasında da anlamlı bir ilişki olduğu gözlenmiştir $(p=0,003)$. Çalışmaya katılanların $\% 82,6$ 'sı günde iki saatten az televizyon izlemektedir. Günde iki saatten az televizyon izleyenlerin \%23,3'ü, iki saatten fazla izleyenlerin ise \%37,4'ünün internet bağımlısı olduğu görülmüştür. Ancak hem televizyon izleme alışkanlığı hem de İ sosyal izolasyonla ilişkili bulunduğu için (13, 43-46), anlamlı görünen bu parametre bahsi geçen iki durumun birbiriyle olan karıştırıcı ilişkisinden kaynaklanıyor olabilir. Bu nedenle bağlantının kanıtlanması için kesitsel tipte olmayan prospektif çalışmalara intiyaç vardır.

Çalışmamızda bazı sınırlılıklar söz konusudur. Çalışmanın herhangi bir müdahale içermemesi, anket çalışması olması nedeni ile etik kurula başvurulmamıştır. Ancak çalışma öncesinde öğrencilere ve velilere bilgilendirilmiş onam formları uygulanmış, yazılı ve sözlü açıklamalarda bulunulmuştur. Araştırmamızda çalışma grubu olarak sadece $6,7,9$ ve 11. sınıf öğrencileriyle, tek ilçe ve sistematik örnekleme ile seçilmeyen, pilot olarak belirlenen dört okulda çalışılmıştır. Çalışma ikinci dönem gerçekleştirildiği için sınav döneminde olan 8. ve 11-12. sınıflar çalışmaya alınmamıştır. Lise döneminden iki sınıfın eksilmesi nedeniyle orta okuldan 8. sınıf yanında eşitlemek adına 5. sınıf da çalışma dışı bırakılmıştır. Çalışmanın yapıldığı dönemde toplam 1035 öğrencinin 685'ine ulaşılabilmiş olması önemli bir sınırlılıktır. Bu nedenlerle farklı örneklem gruplarına genellenmesi uygun değildir. Tablo-4'te belirtilen İB ile yapılan çapraz tablolarda istatistiksel olarak anlamlı bulunan durumlarla internet bağımlılığı grupları arasında regresyon analizi, internet Bağımlılığı Ölçeği grubu "Bağımlı, Risk Grubu ve Bağımlı değil” olarak, çalışmanın bağımlı değişkenini ikili değil üç gruba ayırdığından ve "Bağımlı, Risk Grubu" ya da "Risk Grubu, Bağımlı değil" olarak bir arada gruplandırmak makul bulunmadığından gerçekleştirilememiştir. Ayrıca değerlendirmenin kişinin beyanına dayanan ölçeklerle yapılmasına bağlı olarak getirdiği sınırıııklar söz konusudur. Çalışma kesitsel nitelikte olup İB ile anlamlı ilişki bulunan parametrelerin yönü hakkında yorum yapmak olası değildir. Buna karşı Bornova gibi ülkemizin en kalabalık ilçelerinden birinde hatta bazı Avrupa ülkelerinden daha fazla nüfusa sahip bir ilçede yapılması avantajıdır.

\section{Sonuç}

Çalışmanın yapıldığı okullarda ergenlerde internet bağımlılı̆ı yaygındır. Öğrencilerin güvenli internet kullanımı konusunda bilgileri yetersiz gözükmemektedir. İnternet kullanımı konusunda çocukların eğitimcileri ve aileleri tarafından bilgilendirilmeleri önemlidir. Okullarda verilecek internet kullanımı eğitimlerine ebeveynlerin de dahil edilmeleri, çocuklarının internet kullanımını takip etme becerilerini kazanmaları gerektiği önerilebilir. Araştırmada öğrencilerin azımsanmayacak kısmının "internet bağımlısı" olarak saptanması nedeniyle okullarda bu konuda çalışmalar yapılmasında fayda vardır. 


\section{Kaynaklar}

1. Ceyhan E. Ergen Ruh Sağlığı Açısından Bir Risk Faktörü: İnternet Bağımlılığı. Çocuk ve Gençlik Ruh Sağlığı Dergisi 2008; 15 (2): 109-16.

2. TÜİK (Türkiye İstatistik Kurumu), Hanehalkı Bilişim Teknolojileri Kullanım Araştırması, 2013, Türkiye İstatistik Kurumu. 2013. [cited 12 Apr 2018]. Available from: http://www.tuik.gov.tr/PreHaberBultenleri.do;jsessionid=y5hkbLbp8QDgyMztLw4GcHhBXTVhRCN3ZqLPKGNn1 VOsMWc0ZJ1X!1214994832?id=13569

3. TÜiK, "Türkiye İstatistik Kurumu, Hanehalkı Bilişim Teknolojileri Kullanım Araştırması, 2017," Türkiye İstatistik Kurumu. 2017. [cited 12 Apr 2018]. Available from: http://www.tuik.gov.tr/PreHaberBultenleri.do?id=24862

4. Balcı Ş, Gülnar B. Üniversite Öğrencileri Arasında İnternet Bağımlılığı ve İnternet Bağımlılarının Profili. Selçuk Üniversitesi İletişim Fakültesi Akad Dergisi 2009; 6 (1): 5-22.

5. Cheng C, Li A. Y. Internet Addiction Prevalence and Quality of (Real) Life: A Meta-Analysis of 31 Nations Across Seven World Regions. Cyberpsychology, Behav Soc Netw 2014; 17 (12): 755-60.

6. Şaşmaz T. et al. Prevalence and risk factors of Internet addiction in high school students. Eur J Public Health 2013; 24 (1): 15-20.

7. Brand M, Young KS, Laier C. Prefrontal Control and Internet Addiction: A Theoretical Model and Review of Neuropsychological and Neuroimaging Findings. Front Hum Neurosci 2014; 8 (May): 1-13.

8. Yuan K, Qin W, Liu Y, Tian J. Internet addiction: Neuroimaging findings. Commun Integr Biol 2011; 4 (6): 637-39.

9. Ho RC et al. The association between internet addiction and psychiatric co-morbidity: A meta-analysis. BMC Psychiatry 2014; 14 (1).

10. Yen JY, Ko CH, Yen CF, Wu HY, Yang MJ. The Comorbid Psychiatric Symptoms of Internet Addiction: Attention Deficit and Hyperactivity Disorder (ADHD), Depression, Social Phobia, and Hostility. J Adolesc Heal 2007; 41 (1): 93-8.

11. Sussman CJ, Harper JM, Stahl JL, Weigle P. Internet and Video Game Addictions: Diagnosis, Epidemiology, and Neurobiology. Child Adolesc. Psychiatr. Clin. N. Am. 2018; 27 (2): 307-26.

12. Çelik A, Çelen FK, Seferoğlu SS. Ortaokul Öğrencilerinin İnternet Bağımlılık Düzeylerinin Çeşitli Değişkenler Açısından İncelenmesi. Akad. Bilişim'14 - XVI. Akad Bilişim Konf Bildir 2014; 373-82.

13. Harman JP, Hansen CE, Cochran ME, Lindsey CR. Liar, Liar: Internet Faking but Not Frequency of Use Affects Social Skills, Self-Esteem, Social Anxiety, and Aggression. CyberPsychology Behavior 2005; 8 (1): 1-6.

14. Doğan A. İnternet bağimliliği yayginliği. Dokuz Eylül Üniversitesi Eğitim Bilimleri Enstitüsü Aile Eğitimi ve Danışmanlığı Anabilim Dalı, 2013. (Yayınlanmamış tez)

15. Günüç $S$, Kayri M. The profile of internet dependency in Turkey and development of internet addiction scale: study of validity and reliability. Hacettepe Üniversitesi Eğitim Fakültesi Dergisi (H. U. Journal of Education) 2010; 39: 220-32.

16. Türkiye İstatistik Kurumu, 06-15 Yaş Grubu Çocuklarda Bilişim Teknolojileri Kullanımı Ve Medya, 2013. [cited 12

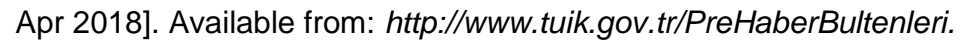
do;jsessionid=y5hkbLbp8QDgyMztLw4GcHhBXTVhRCN3ZqLPKGNn1V0sMWc0ZJ1X!1214994832?id=13569

17. Xin M, Xing J, Pengfei W, Houru L, Mengcheng W, Hong Z. Online activities, prevalence of Internet addiction and risk factors related to family and school among adolescents in China. Addict Behav Reports 2018; 7 (October): 14-8.

18. Çelen FK, Çelik A, Seferoğlu SS. Çocukların İnternet Kullanımları ve Onları Bekleyen Çevrim-İçi Riskler. XIII. Akademik Bilişim Konferansı Bildirileri 2011; 2-4.

19. Koo HJ, Kwon JH. Risk and protective factors of internet addiction: A meta-analysis of empirical studies in Korea. Yonsei Med J 2014; 55 (6): 1691-711.

20. Kim K et al. Internet addiction in Korean adolescents and its relation to depression and suicidal ideation: A questionnaire survey. Int J Nurs Stud 2006; 43 (2): 185-92.

21. Kim K. Association between Internet overuse and aggression in Korean adolescents. Pediatr Int $2013 ; 55$ (6): 703-9.

22. Choi $\mathrm{K}$ et al., Internet overuse and excessive daytime sleepiness in adolescents: Regular article. Psychiatry Clin Neurosci 2009; 63 (4): 455-62.

23. Niemz K, Griffiths M, Banyard P. Prevalence of Pathological Internet Use among University Students and Correlations with Self-Esteem, the General Health Questionnaire (GHQ), and Disinhibition. CyberPsychology Behav 2005; 8 (6): 562-70. 
24. Simkova B, Cincera J. Internet addiction disorder and chatting in the Czech Republic. Cyberpsychol Behav. 2004 Oct; 7 (5): 536-9.

25. Cao H, Sun Y, Wan Y, Hao J, Tao F. Problematic Internet use in Chinese adolescents and its relation to psychosomatic symptoms and life satisfaction. BMC Public Health. 2011 Oct 14; 11: 802.

26. Yang SC, Tung CJ. Comparison of Internet addicts and non-addicts in Taiwanese high school. Comput. Human Behav 2007; 23 (1): 79-96.

27. Johansson A, Götestam KG. Internet addiction: characteristics of a questionnaire and prevalence in Norwegian youth (12-18 years). Scand J Psychol. 2004 Jul;45 (3): 223-9.

28. Moreno MA, Jelenchick L, Cox E, Young H, Christakis DA. Problematic internet use among US youth: a systematic review. Arch Pediatr Adolesc Med. 2011 Sep;165 (9): 797-805.

29. Ko CH, Yen JY, Liu SC, Huang CF, Yen CF. The associations between aggressive behaviors and internet addiction and online activities in adolescents. J Adolesc Health. 2009 Jun;44 (6): 598-605.

30. Durkee $\mathrm{T}$, Kaess $\mathrm{M}$, Carli $\mathrm{V}$ et al. Prevalence of pathological internet use among adolescents in Europe: demographic and social factors. Addiction. 2012 Dec; 107 (12): 2210-22.

31. Canan F, Ataoglu A, Nichols LA, Yildirim T, Ozturk O. Evaluation of psychometric properties of the internet addiction scale in a sample of Turkish high school students. Cyberpsychol Behav Soc Netw. 2010 Jun; 13 (3): 317-20.

32. Canan F, Ataoglu A, Ozcetin A, Icmeli C. The association between Internet addiction and dissociation among Turkish college students. Compr Psychiatry. 2012 Jul; 53 (5): 422-6.

33. Dalbudak E, Evren C, Topcu M, Aldemir S, Coskun KS, Bozkurt M, Evren B, Canbal M. Relationship of Internet addiction with impulsivity and severity of psychopathology among Turkish university students. Psychiatry Res. 2013 Dec 30; 210 (3): 1086-91.

34. Yılmaz E, Şahin L, Haseski Hi, Erol O. Lise öğrencilerinin internet bağımlılık düzeylerinin çeşitli değişkenlere göre incelenmesi: Balıkesir ili örneği. Eğitim Bilim. Araştırmaları Derg. 2014; 4 (1): 133-44.

35. Durak Batıgün A, Hasta D. Internet bağımlılığı: Yalnızlık ve kişilerarası ilişki tarzları açısından bir değerlendirme. (Internet addiction: an evaluation in terms of loneliness and interpersonal relationship styles). Anadolu Psikiyatr Derg 2010; 11: 213-19.

36. Durak Batıgün A, Kılıç N. İnternet Bağımlıı̆̆ı ile Kişilik Özellikleri, Sosyal Destek, Psikolojik Belirtiler ve Bazı Sosyo-Demografi k Değişkenler Arasındaki Iliş̧iler. Türk Psikolojisi Derg 2011; 26 (67): 1-10.

37. Şahin M. The internet addiction and aggression among university students. Dusunen Adam 2014; 27 (1): 43-52.

38. Bayraktar F, Gün Z. Incidence and correlates of Internet usage among adolescents in North Cyprus. Cyberpsychol Behav. 2007 Apr; 10 (2): 191-7.

39. Çakır Balta Ö, Horzum MB. Web Tabanlı Öğretim Ortamındaki Öğrencilerin İnternet Bağımııı̆ını Etkileyen Faktörler. J Fac Educ Sci. 2008; 41 (1):187-205.

40. Esen E, Siyez DM. Ergenlerde İnternet Bağımlılığını Yordayan Psiko-sosyal Değişkenlerin İncelenmesi. Türk Psikolojik Danışma ve Rehb Derg. 2011; 4(36):127-36.

41. Evren C, Dalbudak E, Evren B, Demirci AC. High risk of internet addiction and its relationship with lifetime substance use, psychological and behavioral problems among 10th grade adolescents. Psychiatr Danub. 2014; 26 (4): 330-9.

42. Tahiroglu AY, Celik GG, Uzel M, Ozcan N, Avci A. Internet use among Turkish adolescents. Cyberpsychol Behav. 2008 Oct;11 (5): 537-43.

43. Yang CK. Sociopsychiatric characteristics of adolescents who use computers to excess. Acta Psychiatr Scand. 2001 Sep; 104 (3): 217-22.

44. Chele G, Chirita V, Stefanescu C, Macarie G, llinca M. The Children Lost in Cyberspace? EUROCON 2005 - Int. Conf. "Computer as a Tool," vol. 0: 843-46.

45. Sussman S, Moran MB. Hidden addiction: Television. J Behav Addict. 2013 Sep; 2 (3): 125-32.

46. Kubey R, Csikszentmihalyi M. Television addiction is no mere metaphor. Sci Am. 2002 Feb; 286 (2): 74-80.

47. Finn S, Gorr MB. Social Isolation and Social Support as Correlates of Television Viewing Motivations. Communic Res 1988; 5 (2): 135-58. 